\title{
A Comprehensive Analysis of Mobile Ad-Hoc Routing Protocols Under Varying Node Densities
}

\author{
Manpreet Kaur Kaler \\ Affiliated to PTU (AICTE) \\ Continental Group of Institute \\ $\mathrm{NH}-1$ Jalvehrs, Punjab
}

\author{
Sonia Malhotra \\ Affiliated to PTU (AICTE) \\ BBSBEC Fatehgarh \\ Punjab
}

\begin{abstract}
Mobile ad-hoc network (MANET) is a well known wireless technology being used in present wireless systems and it influences the development of new structures and theories for the communication. The mobile communication in wireless field consists of various nodes communicating with each other through the relay nodes using multi-hope network system or directly. The MANET consists of many routing protocols. Dynamic communication field is mainly dealing area for these routing protocols of MANET. Now-a-days as mobile applications are increasing frequently, It is primary need to analyze these routing protocols to work with high node density and more data load. It motivates the use of various performance comparisons of AODV, DSR and OLSR protocols in mobile ad-hoc network. The comparison represents justified, more effective and reliable protocol for required mobile application. We can analyze these protocols performance on the basis of various matrices like End to End delay, Network load, Re-Transmission attempts and Throughput Using OPNET simulator software tool. The graphical representations are presented here to support the results carried out in this paper.
\end{abstract}

\section{General Terms}

Internet Engineering Task Force (IETF), Wireless Local Area Network (WLAN)

\section{Keywords}

MANET, LAN MAC, AODV, OLSR

\section{INTRODUCTION}

Mobile Ad-Hoc Networks are decentralized wireless systems with autonomous property. These Ad-hoc networks consist of mobile nodes that are free in moving in and out in the network [1]. Nodes are the systems or devices i.e. mobile phone, personal digital assistance, laptop, MP3 player and personal computer that are participating in the network. These nodes can act as host/router or both at same time. They can form arbitrary topologies depending on their connectivity with each other in the network. These nodes have the ability to configure themselves and because of their self configuration ability, they can be deployed urgently without the need of any infrastructure. Internet Engineering Task Force (IETF) has MANET working group (WG) that is devoted for developing IP routing protocols [2]. Routing protocols is one of the challenging and interesting research areas for researchers. Many routing protocols have been developed for MANETS as shown in fig. 1

\section{PROTOCLS}

Several routing protocols have been proposed for the successful deployment of Mobile Ad Hoc Networks (MANETs) [3]. The protocols differ in terms of routing methodologies and the information used to make routing decisions. On the behalf of their different working methodologies, these routing protocols are divided into three different categories:

1 Reactive Protocols

2 Proactive Protocols

3 Hybrid Protocols

\subsection{Reactive protocols}

Also known as On Demand Routing Protocols because they establish routes between nodes only when they are required to route data packets. When a route required by a source node to a destination for which it does not have route information, it starts a route discovery process which goes from one node two another node until it arrives at the destination or a nodes in-between has a route to the destination. Reactive Protocols are generally considered efficient when the route discovery is less frequent that the data transfer because the network traffic caused by the route discovery step is low compared to the total communication bandwidth [4]. This makes the reactive protocols more suitable to the network with light traffic and low mobility. Ad Hoc on Demand Vector Routing Protocol (AODV), Dynamic Source Routing (DSR) are the examples of Reactive Protocols.

\subsection{Proactive protocols}

Also known as Table Driven Protocols. These protocols maintain constantly updated topology of the network. Every node in the network knows about the other nodes in advance keeping it simple, the whole network is known to all the nodes making that network. All the routing information is usually kept in number of different tables [4]. Whenever there is a change in the network topology, these tables are update according to the changes. Optimized Link State Routing Protocol (OLSR), Destination-Sequenced Distance-Vector Routing (DSDV) Protocols are the examples of Proactive Protocols.

\section{DESIGN CHALLENGES}

All The unique characteristics of Mobile Ad Hoc Networks (MANETs) bring many open research issues to the network architecture design and the communication protocols of MANETs, ranging from the application layer to the physical layer. Although their exist recent advances in the Mobile Ad Hoc Networks, many research problems still need to be resolved. Network security needs to be ensured. The critical factors influencing the performance of MANETs can be summarized as follows [5]

\subsection{Advanced Wireless Radio Technologies}

Recently, many solutions have been proposed to improve the capacity of MANETs. Typical examples, include reconfigurable radios, frequency agile/cognitive radios, directional and smart antennas, multiple input multiple output (MIMO) systems, and multi-radio and multi channel systems [5]. Therefore, all these advanced wireless radio technologies 
require a revolutionary design in the communication protocol suite.

\subsection{Network Security}

Denial of service attacks and intrusions in MANETs can cause severe damage to the operation of the deployed network. Although there exists many security schemes proposed for wireless local area networks, most of these security solutions are either not practical or showing poor performance in MANETs because of the lack of a centralized trusted authority to distribute a public key in the MANET architecture.

\subsection{Dynamic Network Connectivity}

In MANETs, to eliminate the single point failures and potential bottleneck links, the wireless backbone needs to provide redundant paths between the sender and the receiver. However, the topology and connectivity of the network can vary frequently because of the route failures and energy depletions.

\subsection{Mobility Support}

In To support mobile clients in MANETs, it is necessary to design advanced physical layer and networking techniques, which adapt to the fast fading conditions commonly associated with the mobile users. In addition to these advanced techniques, low latency handover and location management algorithms are also required to improve the quality of service during mobility.

\subsection{Network Management}

To monitor the overall network performance and maintain the network operation, flexible and scalable network management capabilities are required for MANETs. The primary network management capabilities of the MANETs include: Bandwidth provisioning, Installing security and quality of service policies, Supporting service level agreements, Fault identification and resolution, Addition and removal of network entities, Change of network functions, Accounting, billing and reporting.

\section{PERFORMANCE METRICS}

The main Metrics is a property of a route in computer networking, consisting of any value used by routing algorithms to determine whether one route should perform better than another. The routing table stores only the best possible routes, while link-state or topological databases may store all other information as well. For the comparison of protocols under the applications generating heavy traffic, four different metrics have been chosen [6] as:

\subsection{Re-Transmission Attempts (packets)}

Total number of retransmission attempts by all WLAN MACs in the network, until either packet is successfully transmitted or it is discarded as a result of researching short or long retry limit.

\subsection{Transmission Delay (seconds)}

This is average end to end delay of all successful transmitted data packet. It is used to represent the end to end delay of all the packets received by the wireless LAN MACs of all
WLAN nodes in the network and forwarded to the higher layers.

\subsection{Average Delay $\sum_{\mathbf{i}}^{\mathbf{n}}($ CBR_sent_time_CBR_receive_time) / $\sum_{\mathbf{i}}^{\mathbf{n}}($ CBR_receive)}

\subsection{Network Load (bits/sec)}

This is average end to end delay of all successful transmitted data packet. It is used to represent the end to end delay of all the packets received by the wireless LAN MACs of all WLAN nodes in the network and forwarded to the higher layers.

\section{ANALYZED PROTOCOLS}

\subsection{Optimized Link State Routing (OLSR)}

The Optimized Link State Routing Protocol (OLSR) is a protocol that was developed for mobile ad hoc network (MANET). It is a variation of traditional link state routing, modified for improved operation in ad hoc networks. It is a table driven and proactive routing protocol where the nodes exchange their topology information with other nodes regularly. The routes in the proactive protocols are always immediately available when needed. OLSR is designed to work in a completely distributed manner and does not depend on any central entity. The protocol does not require reliable transmission of control messages [7].

\subsection{Ad-Hoc On Demand Distance Vector (AODV) Routing Protocol}

AODV (Ad-hoc On-demand Distance Vector) is a loop-free routing protocol for ad-hoc networks as shown in Fig. 1. It is designed to be self-starting in an environment of mobile nodes, withstanding a variety of network behaviours such as node mobility, link failures and packet losses. The AODV protocol consists of two important mechanisms, Route Discovery and Route Maintenance. AODV is chosen for the obvious reason that it is simple and has a low overhead and its on-demand nature does not unduly burden the networks.

Fig.1 Laptops Connected in AODV Mode

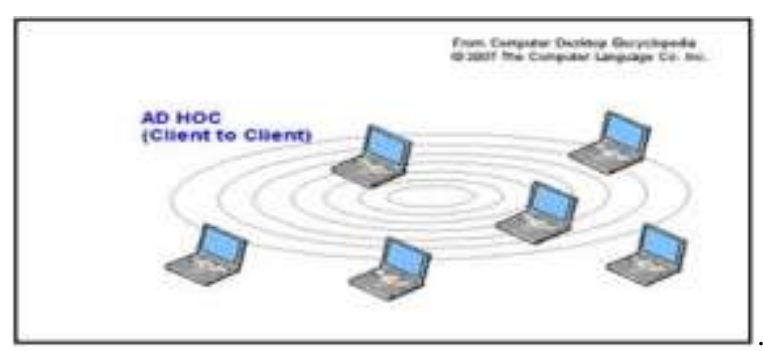

Fig.2 Modeling \& Simulation Cycle 


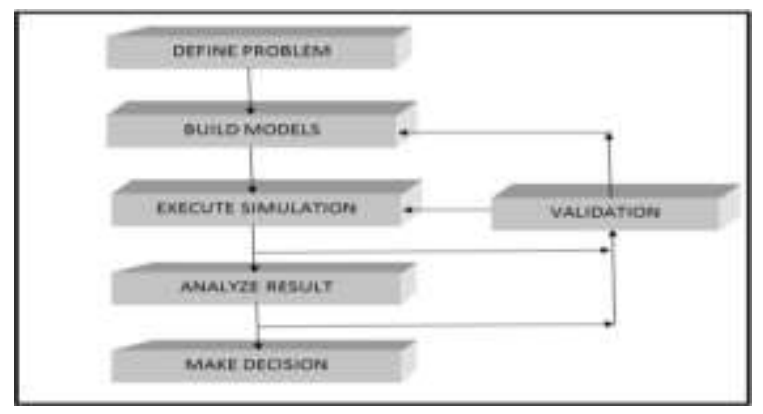

\section{SIMULATION TOOLS}

\subsection{Network Model}

Network Editor is used to specify the physical topology of a communications network, as shown in Fig. 2, which define the position and interconnection of communicating entities, i.e. node and link. A set of parameters or characteristics is attached with each model that can be set to customize the node's behaviour. A node can either be fixed, mobile or satellite. Simplex (unidirectional) or duplex (bi-directional) point-to-point links connects pairs of nodes. A bus link provides a broadcast medium for an arbitrary number of attached devices.

\subsection{Node Model}

Network Communication devices created and interconnected at the network level need to be specified in the node domain using the Node Editor as shown in Fig. 3. These modules can be grouped into two distinct categories. The first set is modules that have predefined characteristics and a set of builtin parameters. Examples are packet generators, point-to-point transmitters and radio receivers. The second group contains highly programmable modules.

\subsection{Process Model}

Fig. 4 shows a Process model, created using the process editor, are used to describe the logic flow and behaviour of processor and queue modules, which consists of state transition diagrams (STDs), a library of kernel procedures, and the standard $\mathrm{C}$ programming language. The OPNET Process Editor uses a powerful state-transition diagram approach to support specification of any type of protocol, resource, application, algorithm, or queuing policy. States and transitions graphically define the progression of a process in response to events. Within each state, general logic can be specified using a library of predefined functions and even the full flexibility of the $\mathrm{C}$ language. Process may create new processes (child process) to perform sub-tasks and thus is called the parent process [9].

\section{Fig.3 Example of a Node Model}

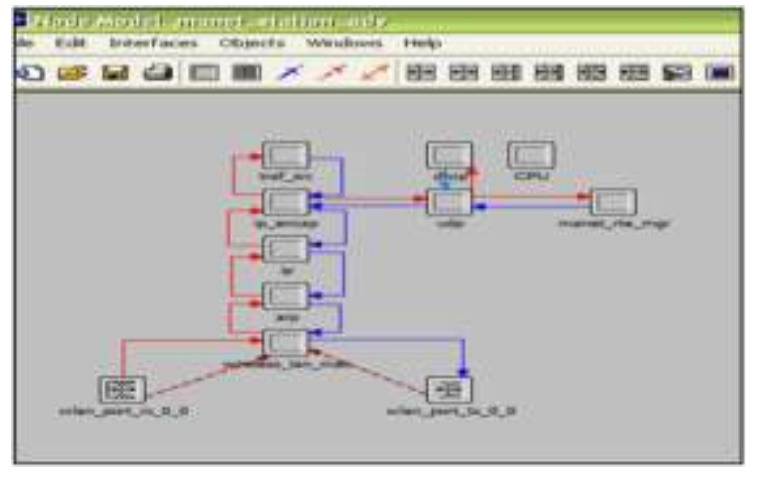

Fig.4 Example of a Process Model

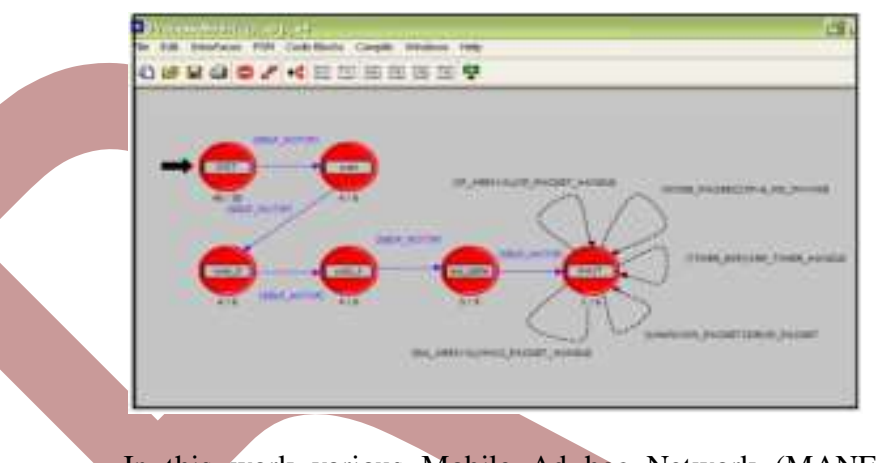

In this work various Mobile Ad hoc Network (MANET) routing protocols have been studied. To choose best among the existing protocols, it is necessary to design few network models for the evaluation of the performance of these protocols. In this chapter, various network models to carry out the simulations are discussed. At the end of this chapter, results obtained from various simulations in the form of graphs are presented. Future work is also suggested.

\section{APPLICATION EXAMPLES}

Creating the simulation scenario that is equivalent to real world is the first step of simulation as shown in Fig. 5 \& Fig. 6 . In this study, several network scenarios are created. All these scenarios are categorised on the behalf of nodes densities, such that, number of nodes present in the network. Five node densities are simulated i.e. 20, 40, 60, 80, 100 nodes. As shown in Table $1 \&$ Fig.7 we are using GSM Voice Application Parameters as an example.

Fig.5 Application Example with 20 Mobility Nodes

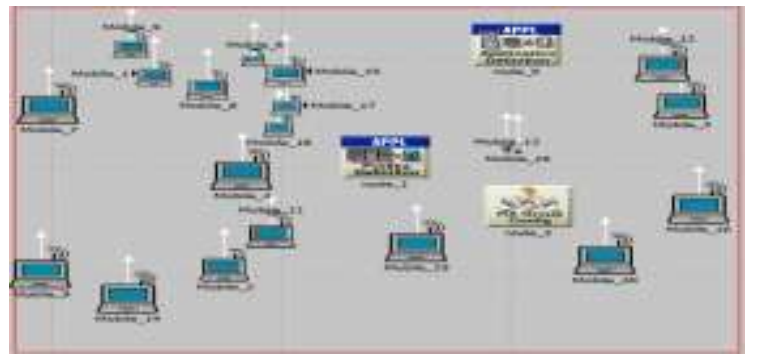




\section{Fig.5 Application Example with 120 Mobility Nodes}

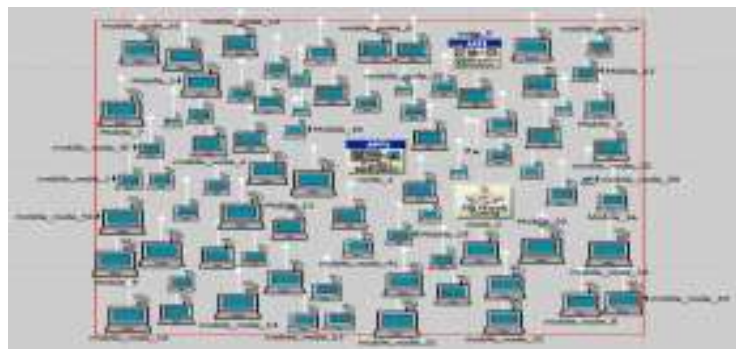

Table 1. GSM Voice Application Parameters

\begin{tabular}{|l|l|}
\hline Incoming encoder scheme & GSM FR (Full Rate) \\
\hline Outgoing encoder scheme & GSM FR (Full rate) \\
\hline Voice Frames per Packet & 1 \\
\hline Compression Delay (sec) & .02 \\
\hline Decompression Delay (sec) & .02 \\
\hline RSVP Parameters & None \\
\hline
\end{tabular}

\subsection{Wireless parameters}

The wireless parameters are common to all of the routing protocols as shown in table 2 . The buffer size was set to 102400000 bits as heavier flow of application was generated. In addition, the channel settings were set to "auto assigned" in order to avoid manual error.

\section{Fig.7.GSM Voice Application Configuration}

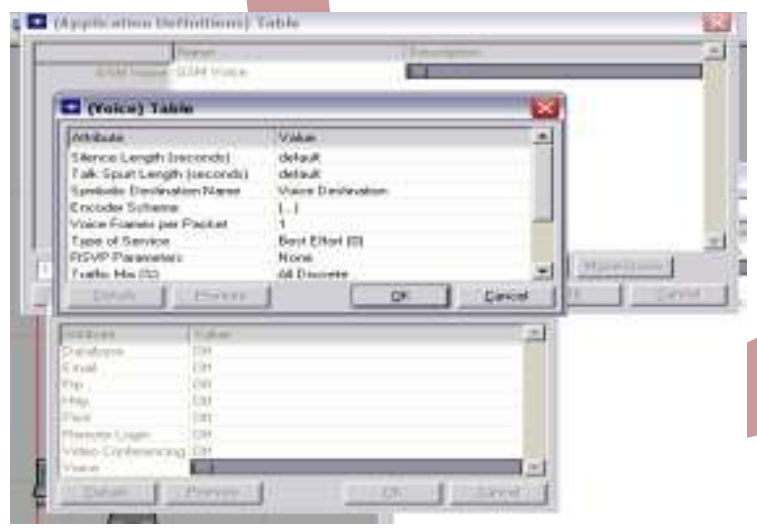

Table 2. Wireless LAN Parameters Used

\begin{tabular}{|c|c|c|}
\hline S.No & Parameters & Values \\
\hline 1. & Data Rate & $2 \mathrm{Mbps}$ \\
\hline 2. & Simulation Area & $1000 \mathrm{x} 1000$ Meters \\
\hline 3. & Route Cache & 50 Routes \\
\hline 4. & Node Mobility & Random Waypoint \\
\hline 5. & Transmission Range & 250 Meters \\
\hline
\end{tabular}

\begin{tabular}{|c|c|c|}
\hline 7. & Size of Data Packets & 64 byte \\
\hline 8. & Packet Interval & $\begin{array}{c}\text { Constant Rate(50 } \\
\text { packets/ sec })\end{array}$ \\
\hline 9. & Node Speed & Uniform $(0,20) \mathrm{m} / \mathrm{s}$ \\
\hline 10. & Hop Delay & $1.2 \mu \mathrm{s}$ \\
\hline 11. & $\begin{array}{c}\text { Transmission Delay } \\
\text { Window }\end{array}$ & $30 \mathrm{~ms}$ \\
\hline
\end{tabular}

\section{SIMULATION RESULT \&}

\section{ANALYSIS}

After choosing metrics, the simulation is done for 11 minutes for each scenario. Then results are obtained as:

\subsection{Transmission Delay(various node densities)}

Figure 8 shows delay in an AODV network. When the number of nodes were increased from 20 to 40, then the delay to transmit data in the network was increased by $55.3 \%$. But when, we go on increasing the number of nodes in the network and reached to 100 nodes i.e. from 20 to 40,40 to 60,60 to 80 , then at each level delay is decreased from the previous level. Same effect had been seen in the case of DSR protocol (Fig. 9). This is because AODV and DSR, both are reactive protocols and when there are less number of nodes in a same geographical area then the nodes take more time to find their neighbours to establish routes between the sender and receiver.

Fig.8.End to End Delay for Low Density Network

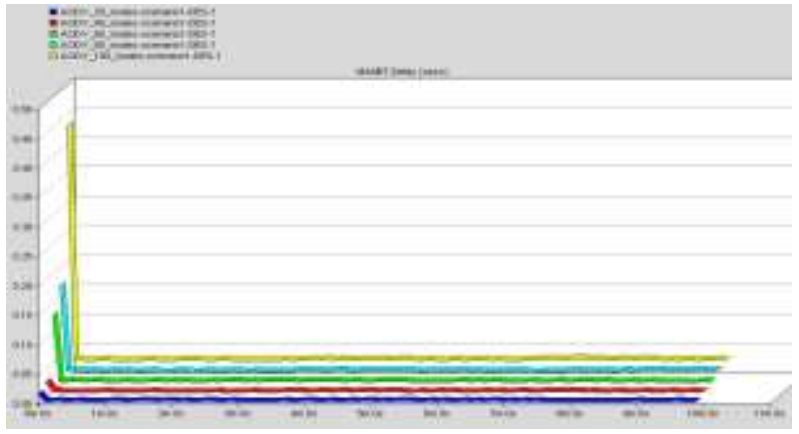

Table 3. Transmission Delay in AODV Protocol (sec.)

\begin{tabular}{|l|l|l|l|l|l|}
\hline $\begin{array}{l}\text { Simulatio } \\
\mathrm{n} \text { time } \\
(\mathrm{sec})\end{array}$ & $\begin{array}{l}\text { AODV } \\
(20 \\
\text { Nodes })\end{array}$ & $\begin{array}{l}\text { AODV } \\
(40 \\
\text { Nodes })\end{array}$ & $\begin{array}{l}\text { AODV } \\
(60 \\
\text { Nodes })\end{array}$ & $\begin{array}{l}\text { AODV } \\
(80 \\
\text { Nodes })\end{array}$ & $\begin{array}{l}\text { AODV } \\
(100 \\
\text { Nodes })\end{array}$ \\
\hline 2 & .0047 & .0098 & .022 & .03 & .05 \\
\hline 4 & .0042 & .0095 & .019 & .025 & .04 \\
\hline 6 & .0041 & .0095 & .018 & .025 & .04 \\
\hline 8 & .0041 & .0093 & .018 & .024 & .04 \\
\hline 10 & .0040 & .0093 & .017 & .024 & .03 \\
\hline Average & .0042 & .0094 & .018 & .025 & .04 \\
\hline
\end{tabular}

w w w. cir world. com 


\begin{tabular}{|l|l|l|l|l|}
\hline Increased by (\%) & $55.3 \%$ & $47.7 \%$ & $28 \%$ & $37.5 \%$ \\
\hline
\end{tabular}

Fig.9 Transmission Delay in DSR (sec)

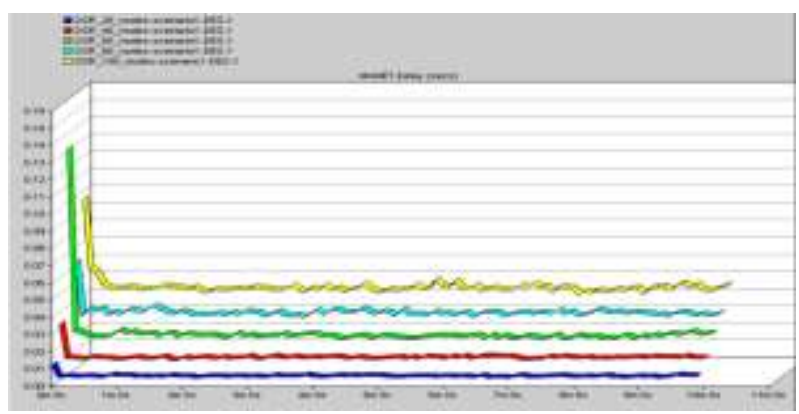

Table 4 Transmission Delay in DSR

\begin{tabular}{|l|l|l|l|l|l|}
\hline $\begin{array}{l}\text { Simulation } \\
\text { time }(\mathrm{sec})\end{array}$ & $\begin{array}{l}\text { DSR } \\
(20 \\
\text { Nodes })\end{array}$ & $\begin{array}{l}\text { DSR } \\
(40 \\
\text { Nodes })\end{array}$ & $\begin{array}{l}\text { DSR } \\
(60 \\
\text { Nodes })\end{array}$ & $\begin{array}{l}\text { DSR } \\
(80 \\
\text { Nodes })\end{array}$ & $\begin{array}{l}\text { DSR } \\
(100 \\
\text { Nodes })\end{array}$ \\
\hline 2 & .0057 & .0135 & .029 & .034 & .042 \\
\hline 4 & .0052 & .013 & .026 & .033 & .04 \\
\hline 6 & .0052 & .013 & .024 & .0325 & .04 \\
\hline 8 & .00515 & .0125 & .023 & .0325 & .04 \\
\hline 10 & .00515 & .0125 & .022 & .0325 & .04 \\
\hline Average & .00528 & .0129 & .0248 & .0329 & .0404 \\
\hline \multicolumn{2}{|l|}{ Increased by $(\%)$} & $59.06 \%$ & $47.9 \%$ & $24.6 \%$ & $18.56 \%$ \\
\hline
\end{tabular}

Fig.10Transmission Delay in OLSR Protocol (sec)
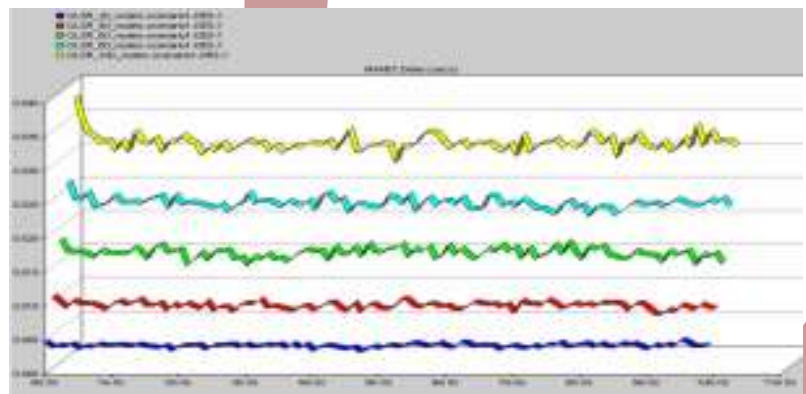

Table 5 Transmission delay in OLSR

\begin{tabular}{|l|l|l|l|l|l|}
\hline $\begin{array}{l}\text { Simulation } \\
\text { time }(\mathrm{sec})\end{array}$ & $\begin{array}{l}\text { OLSR } \\
(20 \\
\text { Nodes })\end{array}$ & $\begin{array}{l}\text { OLSR } \\
(40 \\
\text { Nodes })\end{array}$ & $\begin{array}{l}\text { OLSR } \\
(60 \\
\text { Nodes })\end{array}$ & $\begin{array}{l}\text { OLSR } \\
80 \\
\text { Nodes })\end{array}$ & $\begin{array}{l}\text { OLSR } \\
(100 \\
\text { Nodes })\end{array}$ \\
\hline 2 & .000425 & .00055 & .00071 & .0009 & .0011 \\
\hline 4 & .00043 & .00056 & .00070 & .0009 & .00115 \\
\hline 6 & .00043 & .00057 & .00070 & .0009 & .00113 \\
\hline 8 & .000435 & .00056 & .000715 & .0009 & .00115 \\
\hline 10 & .00044 & .00056 & .00072 & .0009 & .00115 \\
\hline Average & .000432 & .00056 & .000709 & .0009 & .001136 \\
\hline \multicolumn{2}{|l|}{ Increased by $(\%)$} & $22.85 \%$ & $21.01 \%$ & $21.22 \%$ & $20.77 \%$ \\
\hline
\end{tabular}

\subsection{Network Load at high nodal mobility}

The network load only calculated by using successfully transmitted packets excluding the dropped packets. Graph (Fig. 11) depicts that as the network becoming large, the data dropped for the network configured by using AODV protocol is increased due to which the network load decreased. In the Table 6 , it is shown that when the number of nodes in a network are increased from 20 to 40 then network load is increased by $50 \%$ but when from 40 nodes, number of nodes are getting increased up to 100 nodes then the increment in the network load is limited to just $29.2 \%$.

Fig. 11 Network load in AODV (bits/sec)

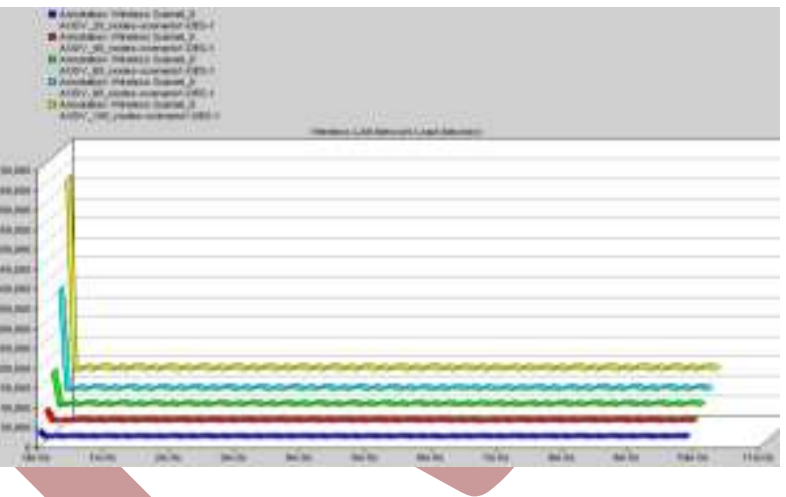

Table 6 Network Load in AODV Protocol

\begin{tabular}{|l|l|l|l|l|l|}
\hline $\begin{array}{l}\text { Simulatio } \\
\mathrm{n} \text { time } \\
(\mathrm{sec})\end{array}$ & $\begin{array}{l}\text { AODV } \\
(20 \\
\text { Nodes })\end{array}$ & $\begin{array}{l}\text { AODV } \\
(40 \\
\text { Nodes })\end{array}$ & $\begin{array}{l}\text { AODV } \\
(60 \\
\text { Nodes })\end{array}$ & $\begin{array}{l}\text { AODV } \\
(80 \\
\text { Nodes })\end{array}$ & $\begin{array}{l}\text { AODV } \\
(100 \\
\text { Nodes })\end{array}$ \\
\hline 2 & 25200 & 50000 & 79000 & 110000 & 160000 \\
\hline 6 & 24800 & 49800 & 77000 & 102000 & 145000 \\
\hline 8 & 24800 & 49700 & 76000 & 101000 & 140000 \\
\hline 10 & 24800 & 49500 & 75000 & 100000 & 140000 \\
\hline Average & 24800 & 49500 & 75000 & 100000 & 140000 \\
\hline \multicolumn{2}{|l|}{ Increased by $(\%)$} & 49700 & 76400 & 102600 & 145000 \\
\hline
\end{tabular}

Fig. 12 Network Load in DSR Protocol (bits/sec)

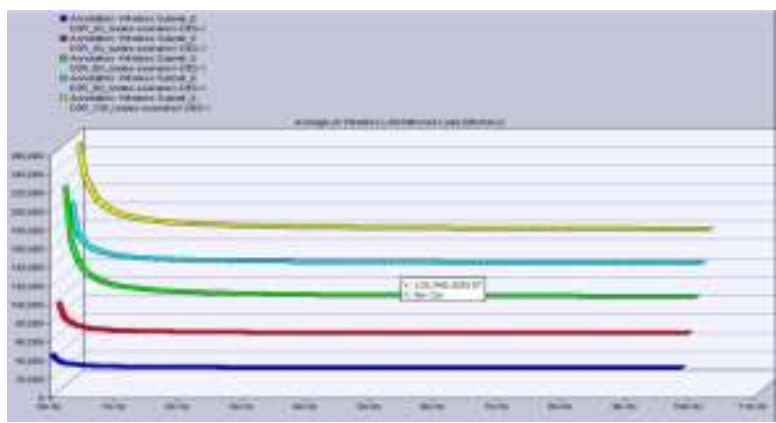

Table 7. Network Load in DSR Protocol

\begin{tabular}{|c|c|c|c|c|c|}
\hline $\begin{array}{l}\text { Simulation } \\
\text { time (sec) }\end{array}$ & $\begin{array}{l}\text { DSR } \\
(20 \\
\text { Nodes })\end{array}$ & $\begin{array}{l}\text { DSR } \\
(40 \\
\text { Nodes) }\end{array}$ & $\begin{array}{l}\text { DSR } \\
(60 \\
\text { Nodes })\end{array}$ & $\begin{array}{l}\text { DSR } \\
(80 \\
\text { Nodes) }\end{array}$ & $\begin{array}{l}\text { DSR } \\
(100 \\
\text { Nodes })\end{array}$ \\
\hline
\end{tabular}




\begin{tabular}{|l|l|l|l|l|l|}
\hline 2 & 32000 & 63000 & 100000 & 128000 & 160000 \\
\hline 4 & 31000 & 62500 & 98000 & 127000 & 159000 \\
\hline 6 & 31000 & 62500 & 97000 & 126000 & 158000 \\
\hline 8 & 31000 & 62500 & 97000 & 126000 & 158000 \\
\hline 10 & 31000 & 62500 & 97000 & 125500 & 158000 \\
\hline Average & 31200 & 62600 & 97800 & 126500 & 158600 \\
\hline Increased by (\%) & $50.15 \%$ & $35.9 \%$ & $22.6 \%$ & $20.23 \%$ \\
\hline
\end{tabular}

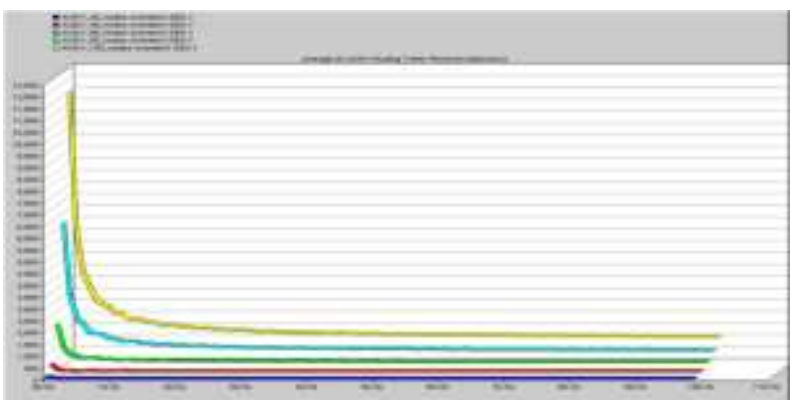

Table 9 Routing Traffic Received in AODV

Fig.13 Network Load in OLSR Protocol (bits/sec)

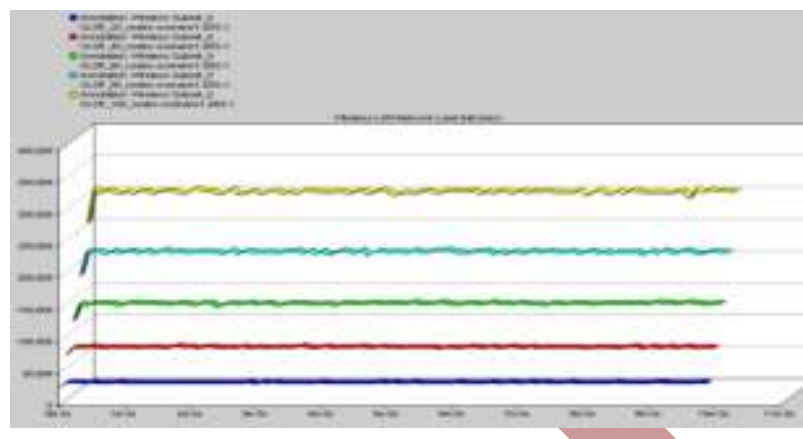

Table 8. Network Load in OLSR Protocol

\begin{tabular}{|c|c|c|c|c|c|}
\hline $\begin{array}{c}\text { Simulation } \\
\text { time (sec) }\end{array}$ & $\begin{array}{c}\text { OLSR } \\
(20 \\
\text { Nodes })\end{array}$ & $\begin{array}{c}\text { OLSR } \\
(40 \\
\text { Nodes })\end{array}$ & $\begin{array}{c}\text { OLSR } \\
(60 \\
\text { Nodes })\end{array}$ & $\begin{array}{c}\text { OLSR } \\
(80 \\
\text { Nodes })\end{array}$ & $\begin{array}{c}\text { OLSR } \\
(100 \\
\text { Nodes })\end{array}$ \\
\hline 2 & 34000 & 81000 & 140000 & 211000 & 290000 \\
\hline 4 & 34000 & 81500 & 140000 & 212000 & 300000 \\
\hline 6 & 34000 & 81500 & 140000 & 213000 & 300000 \\
\hline 8 & 34000 & 81500 & 140000 & 213000 & 300000 \\
\hline 10 & 34000 & 81500 & 140500 & 213000 & 300000 \\
\hline Average & 34000 & 81400 & 140100 & 212400 & 298000 \\
\hline \multicolumn{2}{|c|}{ Increased by (\%) } & $58 \%$ & $41 \%$ & $34 \%$ & $28.72 \%$ \\
\hline
\end{tabular}

\subsection{Routing Traffic Received}

Fig 13 shows average traffic received by all the nodes in AODV configured network in the form packets. Graphs shows that as the number of the nodes in a network is increased then the data losses are also increased and average traffic received by all the nodes in the network is decreased. As shown in (Tables 9, 10, 11) Data dropped in the network and traffic received in the network, both are inversely proportional to each other. When the number of nodes were increased from 20 to 40 then the increment in the traffic received in the network is of $75.42 \%$ but when the number of nodes were reached to 100 then the traffic received by only $36.26 \%$. So as the network size increasing then the traffic receiving is decreasing. Same effect has been seen in the case of DSR protocol but AODV protocol outperforms the DSR protocol.

Fig.14 Routing Traffic OLSR Protocol (bits/sec)

\begin{tabular}{|l|l|l|l|l|l|}
\hline $\begin{array}{l}\text { Simulation } \\
\text { time }(\mathrm{sec})\end{array}$ & $\begin{array}{l}\text { AODV } \\
(20 \\
\text { Nodes })\end{array}$ & $\begin{array}{l}\text { AODV } \\
(40 \\
\text { Nodes })\end{array}$ & $\begin{array}{l}\text { AODV } \\
(60 \\
\text { Nodes })\end{array}$ & $\begin{array}{l}\text { AODV } \\
(80 \\
\text { Nodes })\end{array}$ & $\begin{array}{l}\text { AODV } \\
(100 \\
\text { Nodes })\end{array}$ \\
\hline 2 & 193 & 790 & 1760 & 3180 & 4900 \\
\hline 4 & 192 & 780 & 1750 & 3170 & 4900 \\
\hline 6 & 191 & 780 & 1760 & 3170 & 4900 \\
\hline 8 & 190 & 770 & 1760 & 3170 & 4900 \\
\hline 10 & 190 & 770 & 1750 & 3170 & 4900 \\
\hline Average & 191.2 & 778 & 1756 & 3172 & 4900 \\
\hline Increased by (\%) & $75.42 \%$ & $55.69 \%$ & $44.64 \%$ & $35.26 \%$ \\
\hline
\end{tabular}

Fig.15 Routing Traffic Received in OLSR (pkt/sec)

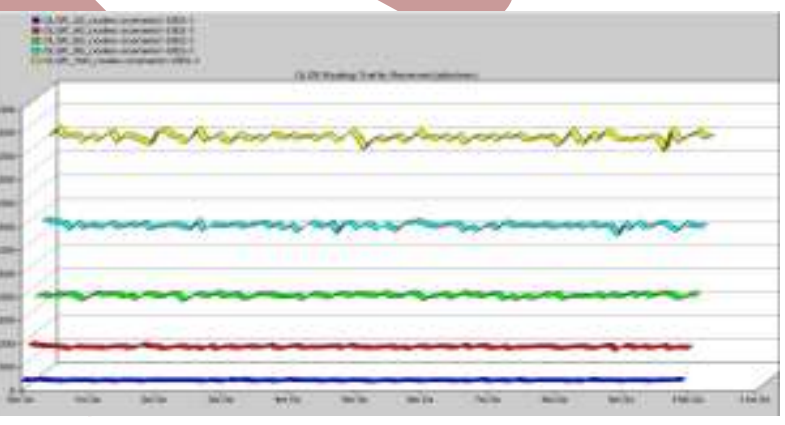

Table.10 Routing Traffic Received in OLSR Proto

\begin{tabular}{|l|l|l|l|l|l|}
\hline $\begin{array}{l}\text { Simulation } \\
\text { time }(\mathrm{sec})\end{array}$ & $\begin{array}{l}\text { OLSR } \\
(20 \\
\text { Nodes })\end{array}$ & $\begin{array}{l}\text { OLSR } \\
(40 \\
\text { Nodes })\end{array}$ & $\begin{array}{l}\text { OLSR } \\
(60 \\
\text { Nodes })\end{array}$ & $\begin{array}{l}\text { OLSR } \\
(80 \\
\text { Nodes })\end{array}$ & $\begin{array}{l}\text { OLSR } \\
(100 \\
\text { Nodes })\end{array}$ \\
\hline 2 & 193 & 790 & 1760 & 3180 & 4900 \\
\hline 4 & 192 & 780 & 1750 & 3170 & 4900 \\
\hline 6 & 191 & 780 & 1760 & 3170 & 4900 \\
\hline 8 & 190 & 770 & 1760 & 3170 & 4900 \\
\hline 10 & 190 & 770 & 1750 & 3170 & 4900 \\
\hline Average & 191.2 & 778 & 1756 & 3172 & 4900 \\
\hline \multicolumn{2}{|l|}{ Increased by (\%) } & 75.42 & 55.69 & 44.64 & 35.26 \\
\hline
\end{tabular}

\section{Conclusion \& Future Scope}

performance of one proactive protocol, such that, OLSR protocol and two reactive protocols, such that, AODV and DSR has been evaluated. To evaluate the performance of the these protocols difference network scenarios has been designed with five different node densities, such that, 20 nodes, 40 nodes, 60 nodes, 80 nodes and 100 nodes. Network 
performance is measured in terms of transmission delay, network load, routing traffic received and throughput. After the intensive simulations done by using a discrete event simulator called OPNET, it has been concluded that from both reactive protocols, such that, AODV and DSR, AODV outperformance the DSR protocol because it has shown lest effectiveness of node densities over the performance of the network configured by using AODV protocol. Same effect has been shown by OLSR protocol over AODV protocol and outperforms the OLSR protocol. So it can be said that proactive protocols are less prone to varying node densities in the network than the reactive protocols. There is always a scope of improvement in the evaluated results. More evaluations of other MANET routing protocols, such that, BABLE, ZRP, DSDV etc can be done by using more variations in the node densities in the networks to make the concluded results more justified.

\section{ACKNOWLEDGMENTS}

Our thanks to all seniors \& expert persons to contribute and guide throughout the review of paper title" A Comprehensive Analysis of Mobile Ad-Hoc Routing Protocols Under Varying Node Densities"

\section{REFERENCES}

[1] Sahadevaiah, K. and Ramanaiah, O.B.V. (2010), "An Empirical Examination of Routing Protocols in Mobile Ad Hoc Networks" in International Journal of Communications, Network and System Sciences, 2010, 3, 511-522.

[2] Pei, G., Gerla, M., Hong, X. and Chiang, C. (1999), "A wireless hierarchical routing protocol with group mobility" In Proceedings of the IEEE Wireless Communications and Networking Conference (WCNC), 312-318.

[3] Rubin, I. and Choi, C. (1997), "Impact of the lcation area structure on the performance of signaling channels in wireless cellular networks" IEEE Communications Magazine, pages 108-115.
[4] Yassein, M.B., Khaouaz, S. YOM.O., Papanastasiou, S. and Al-Ayyou, A. (2007), "On the effect of Mobility and Density on Probabilistic Flooding in MANETs" In IJCSNS International Journal of Computer Science and Network Security, Pages 201-215, VOL.6 No.3.

[5] Rahman, Abdul Hadi and Zukarnain, Zuriati Ahmad (2009), "Performance Comparison of AODV, DSDV and I-DSDV Routing Protocols in Mobile Ad Hoc Networks" in European Journal of Scientific Research, ISSN 1450-216X, Vol.31, No.4 pp. 566-576.

[6] Shrestha, A. and Tekiner, F. (2009), "On MANET Routing Protocols for Mobility and Scalability." In International Conference on Parallel and Distributed Computing, Applications and Technologies, Pages 451-456, IEEE Computer Society.

[7] Royer, E. M. and Perkins, C. (1999), "Multicast operation of the ad-hoc on-demand distance vector routing protocol" In Proceedings of the ACM/IEEE International Conference on Mobile Computing and Networking (MOBICOM), pages 207-218.

[8] Johnson, D. and Maltz, D. (1996), "Dynamic source routing in ad hoc wireless networks" In Imelinsky, T., and Korth, H., editors, "Mobile Computing", pages 153-181. Kluwer Academic Publishers.

[9] Karp, B. (2000), MANAT : A tool for mobile and radio communications. $\mathrm{PhD}$ thesis, Harvard University.

[10] Liang, B. and Haas, Z. (1999), "Predictive distance-based mobility management for PCS networks". In Proceedings of the Joint Conference of the IEEE Computer and Communication Societies (INFOCOM).

[11] Tang, D. and Baker, M. (1999), "Analysis of a metropolitan-area wireless network" In Proceedings of the ACM/IEEE International Conference on Mobile Computing and Networking (MOBICOM), pages 13-23. 